\title{
Maternal C677T variant in MTHFR gene as a risk factor of neural tube defect: A case study
}

\author{
Wenchao Sun*, Xiaohong Song, Lin Zhang and Xiaoyang Fei \\ Center of Reproductive Medicine, Hangzhou Women's Hospital, Hangzhou, China
}

\begin{abstract}
Methylenetetrahydrofolate reductase (MTHFR) gene polymorphism has been reported to be a genetic risk factor for neural tube defects (NTDs), but the results in the literatures are inconclusive. Here we report a 34-year-old pregnant woman with heterozygous for the C677T variant in MTHFR gene. She underwent medical abortion for ultrasonographic features suggesting exencephaly. After delivery exencephaly was confirmed via gross pathology. Her childbirth process and postpartum recovery were uneventful. The presented case supports the concept that MTHFR C677T polymorphism is associated with NTD susceptibility. We suggest that women with MTHFR C677T polymorphism should be genetically counselled before they achieve pregnancy again.
\end{abstract}

\section{Introduction}

The relationship of the methylenetetrahydrofolate reductase (MTHFR) gene polymorphism and neural tube defects (NTDs) susceptibility has been widely discussed, but the results are inconclusive. Here we report a pregnant woman with heterozygous for the C677T variant in MTHFR gene. Exencephaly was confirmed via gross pathology after delivery.

\section{Case presentation}

A 34-year-old female (gravida 2, para 1) presented to our hospital for ultrasonographic features suggesting exencephaly, a type of NTDs, at 12 weeks and 3 days of gestation. A confirmatory ultrasonography performed in our hospital at 13 weeks of gestational age showed the absence of the fetal calvarium and disorganized mass of brain tissue, which were consistent with exencephaly. Her medical history was unremarkable except for ankylosing spondylitis from which she had been suffering for 5 years. But recently the disease was under control. Her menstrual cycle was regular, with the length of cycle being 28 days, while bleeding lasting 6 days. Her first pregnancy ended with emergency cesarean delivery due to fetal distress. She has not experienced any other surgery. During this pregnancy, she did not come into contact with poisons or radiation. Her plasma homocysteine level was $25 \mu \mathrm{mol} / \mathrm{L}$ (normal $5 \sim 15 \mu \mathrm{mol} / \mathrm{L}$ ). Genetic analysis of C677T polymorphism in MTHFR gene of the pregnant women showed heterozygous for the C677T variant.

After signing the informed consent, medical abortion (mifepristone $200 \mathrm{mg}$ orally followed by misoprostol $600 \mu \mathrm{g}$ orally) was performed for termination of the pregnancy. A non-viable fetus, in accordance with a gestational age of 13 weeks, had anatomic abnormality of exencephaly. The placenta had no areas of infarction. Postpartum recovery was uneventful (Figures 1, 2).

\section{Discussion}

Epidemiological studies have exhibited that periconceptional lack of folic acid supplementation significantly raises the incidence of women with NTD-affected pregnancies. folate metabolism is associated

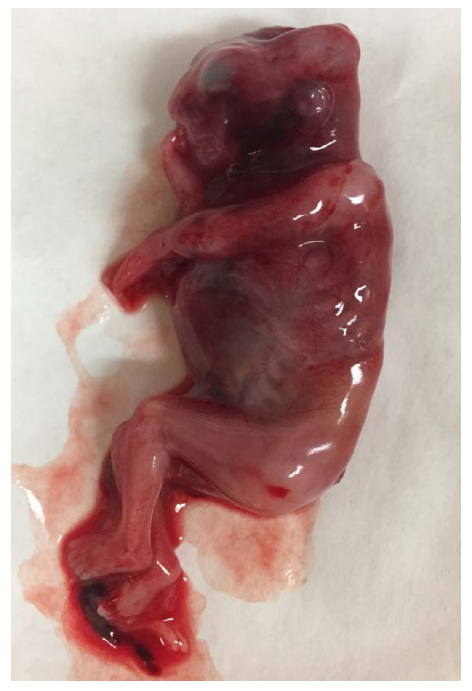

Figure 1. Gross pathology showed exencephaly

with an important enzyme that is MTHFR. The enzyme MTHFR plays a critical role in the folate metabolism pathway and controls the intracellular folate pool for synthesis of DNA. Several single nucleotide polymorphisms in the MTHFR gene have been recognized, with the C677T polymorphism being the most important and best studied one $[1,2]$. The C-T transition at nucleotide 677 is a point mutation which converts a cytosine $(\mathrm{C})$ to a thymine $(\mathrm{T})$, leading to an amino acid

${ }^{*}$ Correspondence to: Wenchao Sun, Center of Reproductive Medicine, Hangzhou Women's Hospital, 369 Kunpeng Road, Hangzhou 310008, China, Tel: +86 571 56005000; Fax: +86 571 56005013; E-mail: attendingsun@sina.com

Key words: C677T variant, exencephaly, methylenetetrahydrofolate reductase (MTHFR) gene, neural tube defects, polymorphism

Received: September 20, 2018; Accepted: September 26, 2018; Published: September 28, 2018 


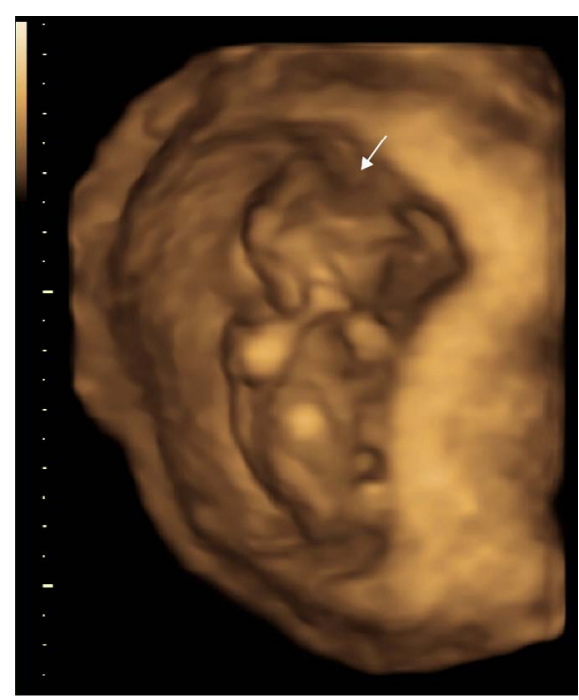

Figure 2. 3D ultrasonography showed exencephaly (arrow) at 13 weeks of gestational age

substitution of alanine to valine. This mutation could lower enzyme activity, reduces concentration of folate in the serum, and adds to total plasma homocysteine concentrations, which in accordance with the elevated plasma homocysteine levels in mothers with NTD-affected offspring. The relationship of the MTHFR C677T polymorphism and NTD susceptibility has been widely revealed, but the results are inconclusive [1]. Despite this, the presented case supports the concept that MTHFR C677T polymorphism is associated with NTD susceptibility. Women with MTHFR C677T polymorphism should be genetically counselled before they achieve pregnancy again.

\section{Conclusion}

We know, however, NTDs have a multifactorial etiology. Various genetic and environmental factors should be taken into consideration. A case study does not allow making a definite conclusion, more research is need in order to make a correct conclusion.

\section{Funding information}

This work is supported by the Medical and Health Science and Technology Plan Project of Zhejiang Province (Grant No. 2015KYB305).

\section{Conflict of interest}

The authors declare that they have no competing interests.

\section{References}

1. Yang Y, Chen J, Wang B, Ding C, Liu H (2015) Association between MTHFR C677T polymorphism and neural tube defect risks: a comprehensive evaluation in three groups of NTD patients, mothers, and fathers. Birth Defects Res A Clin Mol Teratol 103: 488500. [Crossref]

2. Yan L, Zhao L, Long Y, Zou P, Ji G, et al. (2012) Association of the maternal MTHFR C677T polymorphism with susceptibility to neural tube defects in offsprings: evidence from 25 case-control studies. PloS One 7: e41689. [Crossref]

Copyright: (C2018 Sun W. This is an open-access article distributed under the terms of the Creative Commons Attribution License, which permits unrestricted use, distribution, and reproduction in any medium, provided the original author and source are credited. 